\title{
Building failure in South Tel Aviv: case study
}

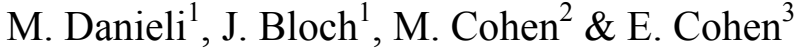 \\ ${ }^{I}$ Department of civil Engineering, the Judea and Samaria College, Ariel, \\ Israel \\ ${ }^{2} R \& D$ Center Samaria and Jordan Rift. Ariel, Israel \\ ${ }^{3}$ Mishael Eng., Tel Aviv, Israel
}

\begin{abstract}
In the middle of January 2006, a very large settlement of the south-eastern corner of a residential building in the southern part of Tel Aviv occurred which resulted in considerable inclination of the building. Because of the danger that the whole building will collapse, a part of the building has been demolished. The foundations of the building, constructed at 1962, were concrete piles cast in clay. The failure of the foundations was the direct reason for the sinking and inclination of the building. The bearing capacities of the piles were lower than the design loads, but despite this the building survived for more than 40 years. This presentation will include: location of the buildings; description of the structure; the foundations; the topographic and land-use changes; the reduction of soil capacity and failure details.
\end{abstract}

Keywords: residential building, structure, foundations, pile, topography, soil capacity, reduction, sinking, inclination, failure, demolish.

\section{Introduction}

The accelerated urban development and the extensive construction works that took place in Israel during the second half of the 20th century, brought to a vast change in land use and, as a result, a severe deterioration of the hydrological and mechanical soil status. Wide areas that were traditionally used as an agricultural land turned into large cities with residential spaces and other accompanied infrastructure like railways highways and industrial zones. Without a careful design, changes in topography and intensive excavation causing brutal violation of the natural equilibrium. In the following case, rapid, non-standard construction of condominiums in the southern part of Tel Aviv brought to a 
failure of a building. Accumulation of water due to poor drainage of the surrounding area increased the soil deformability, decreased soil shearing strength and lowered the bearing capacity of the foundation piles.

\section{Location of the buildings}

The building (fig. 1, 2) is located in the southern part of Tel Aviv (fig. 3).

On its east side there is a regional road and next to it a multi lane Highway. Between the east border of the area and the regional road there is an open public area, $9.5 \mathrm{~m}$ wide, covered with loans and pedestrian walkways. $6 \mathrm{~m}$ south-east of the corner of the building there is an embankment about $3 \mathrm{~m}$ high with a slope toward it.

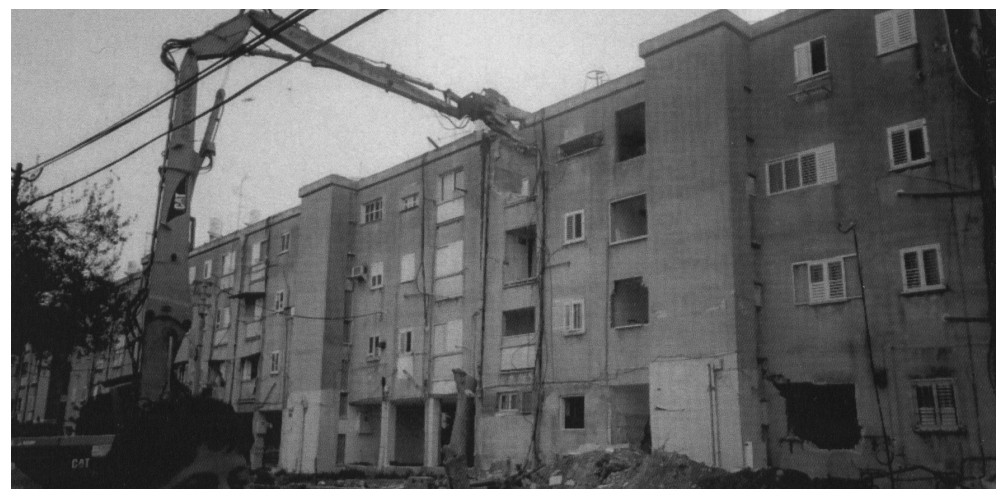

Figure 1: General view of the building.

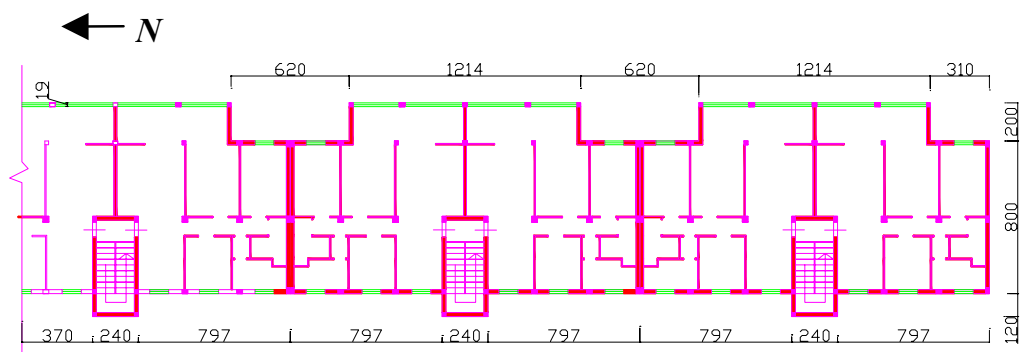

Figure 2: $\quad$ Plan of typical floor (fragment).

An acoustic barrier was constructed on the road border along the building. The distance between the building and the regional road is about $16.5 \mathrm{~m}$. Parallel and $25 \mathrm{~m}$ to the east of the regional road there is a small stream. On the west, $6 \mathrm{~m}$ from the building there is a street. 


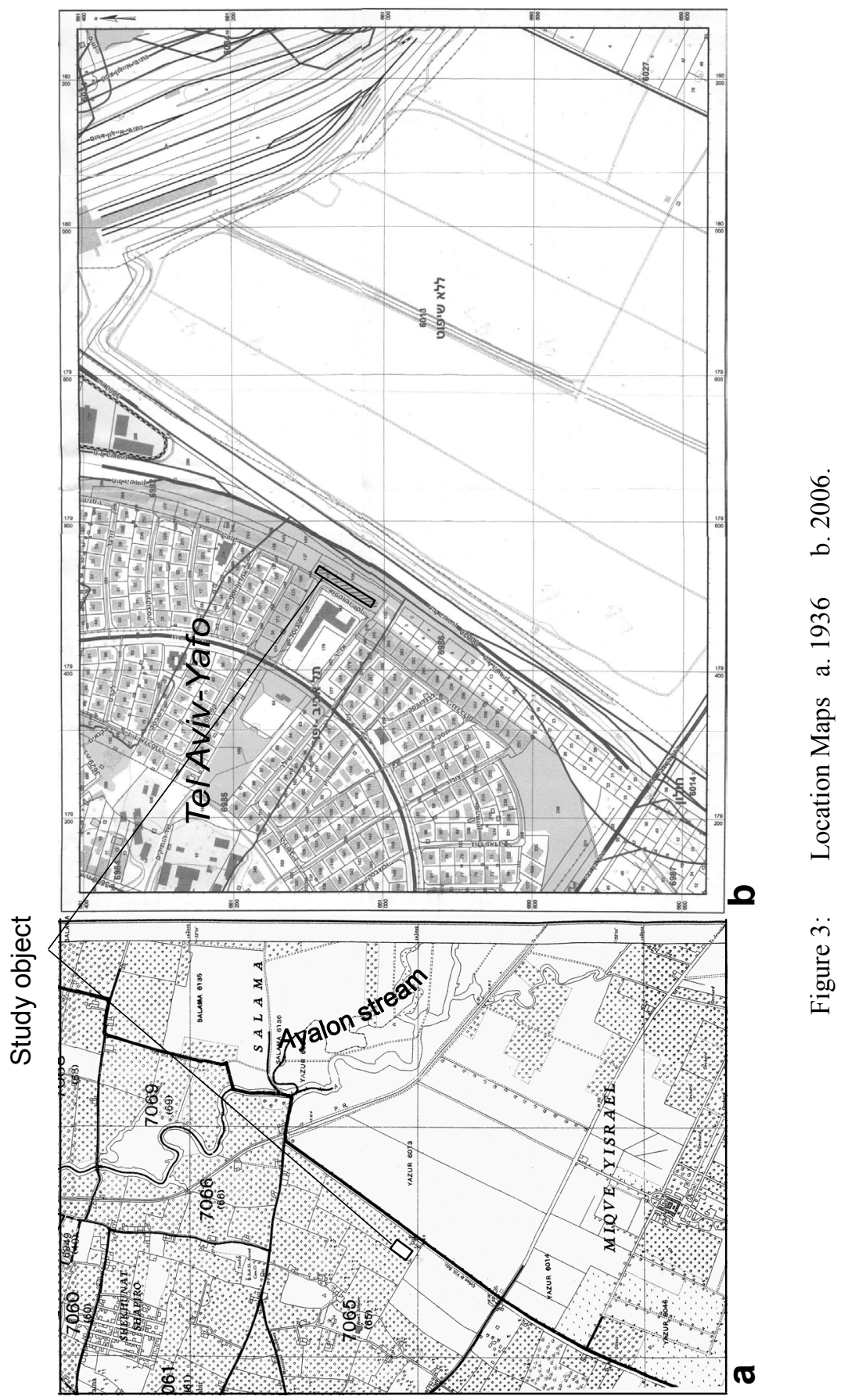

WIT Transactions on The Built Environment, Vol 94, (C) 2007 WIT Press www.witpress.com, ISSN 1743-3509 (on-line) 
On the south, $2.5 \mathrm{~m}$ from the building, an under ground gas reservoir was installed, 1.5 by $2.5 \mathrm{~m}$ and $2 \mathrm{~m}$ deep. $11 \mathrm{~m}$ from the building, a shelter was constructed. On the north, $15 \mathrm{~m}$ from the building, a technical building was constructed. Some technical installations are present in the area of the building. On the south drinking water pipes and the gas reservoir, on the north a municipal drainage conduit, on the west sewage pipe of the building and farther to the west a municipal sewage pipe (under the road).

\section{Description of the structure}

\subsection{General dimensions}

The building, of 4 stories, is $90.7 \mathrm{~m}$ long, $7.0 \mathrm{~m}$ wide and $11.5 \mathrm{~m}$ high is divided into 5 sections by means of 4 expansion joints (fig. 1,2). Each section has a staircase serving 2 apartments every story, no elevators. Underground shelters are located below the first floor and are shared by 2 sections from their 2 staircases. The expansion joints are not cutting the shelters. The structure is made of reinforced concrete, flat slabs $15 \mathrm{~cm}$ thick, as well as the roof, columns $30 \mathrm{X} 30$ $\mathrm{cm}$ spaced $2.8 \mathrm{~m}$ on the alongside and $3.8 \mathrm{~m}$ across. The walls are made of concrete block $20 \mathrm{~cm}$ thick while the partitions are made of $10 \mathrm{~cm}$ concrete blocks. The foundations are reinforced concrete piles cast in-situ.

Thus the building seems to be stable and with sufficient rigidity.

\subsection{The failure}

Only one of the sections failed namely the southern one, to the first expansion joint, $18.2 \mathrm{~m}$ long. This section was demolished by municipality order.

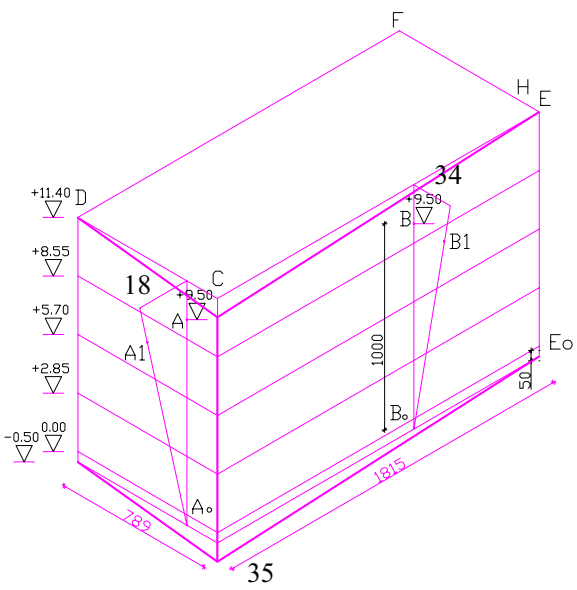

Figure 4: Scheme of the structure deformations. 
The whole structure was checked before the failed section was demolished in order to investigate the reasons of the failure. The failure was expressed by large settlements of the south-east corner and along the southern wall. As a result the whole section was inclined to the south and to the east. The horizontal deflections of the top of the building were measured to be $18 \mathrm{~cm}$ to the south and $34 \mathrm{~cm}$ to the east (fig. 4). The maximal settlement, at the south-east corner, was calculated to be about $35 \mathrm{~cm}$. It is worth noting that those settlements and deflections are far from the allowable values and the acts taken by the municipality were justified. No apparent settlements and damages were detected at the other 4 sections of the building. As an exception a crake was found that opened at the expansion joint that continued it downward. That may be explained by the excessive load imposed on this part of the shelter due to the settlement of the section. The floors of the upper flats were inclined but no visible damages to the concrete skeleton were observed. This means that it can be considered, together with the concrete blocks of the walls and partitions as a rigid box. Near the expansion joint where the section was supported by the shelter, damages in the columns, beams and especially in the partitions were observed (fig. 5) because of the rigidity of the shelter that didn't allowed further settlement, as one unit, of the building. The concrete was tested and found to be above B20. The steel content, as was discovered in the debris, was sufficient. According to the structure analysis it may be concluded that the super structure was stable and capable to withstand the loads imposed. The reason for the large settlements must be found, therefore, in the building foundations.

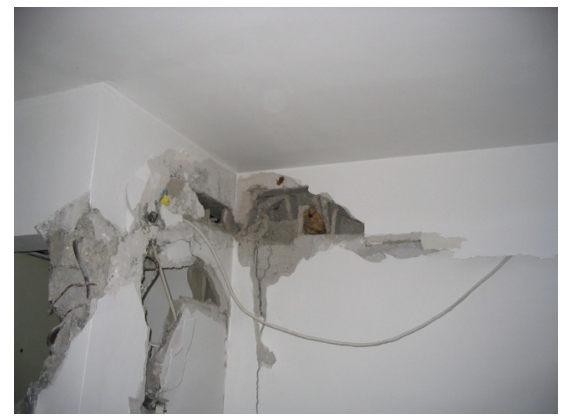

Figure 5: Cracks in structure elements - details.

\section{Subsoil and foundations}

After the section of the building was demolished the subsoil and foundations were investigated. On mid April 2006 an open excavation was executed for testing the geo mechanical properties of the soil and of the foundations. The building was founded on concrete piles 35,40 and $45 \mathrm{~cm}$ diameter and about $6.5 \mathrm{~m}$ long, one pile for each column. The piles were interconnected by the beams of the concrete slab of the ground floor. The concrete class was above B20. By visual inspection no damage was found in the piles. The reinforcement was 5 
bars $12-14 \mathrm{~mm}$ with no signs of corrosion. Soil tests were conducted and the characteristics at $2 \mathrm{~m}$ depth are as following: fat clay, medium consistency, internal friction angle $21^{\circ}$, adhesion $\mathrm{c}=20 \mathrm{kpa}$, initial water content $28.5 \%$ and final $32 \%$, liquid limit 0.63 and plastic index 0.42 . Free water was found at level $-3.2 \mathrm{~m}$. The soil saturated water content is $\sim 38 \%$. Samples of water were sent to laboratory tests and found to be from natural origin. 2 test borings to a depth of $10 \mathrm{~m}$ were executed on July 2006 . The soil was found to be fat clay along the entire depth. Very low water content was detected. It should be noted that the rain season is from October to April with no rains during the rest of the year. The inhabitants of the building said that the shelter was flooded every winter but dried out during the summer.

\section{Changes in land use and hydrology}

\subsection{Surface hydrology}

The region (fig. 3) is a very flat area in the southern part of Tel Aviv city. The average elevation is about 17.5 masl where the natural slope directed north-east toward the lower part of the 815 sq. $\mathrm{km}$ watershed of the Ayalon stream (Musrara Wadi). At the beginning of 20th century most of the area was planted, generally by citrus trees. The area close to stream channel was not cultivated because of the poor drainage conditions and the difficulty of agro technique activities. The main channel of the stream presents a meandering pattern indicating the low energy of the flow due to very small gradients in the heavy clay which fluvial materials deposited by the stream. The area was subjected to frequent floods that prevent the urban development in this area. Straightening of the stream channel and bank reinforcing took place together with the construction of the regional road in 1970. Nevertheless, these measures didn't help the accelerated residential construction to break into the susceptible area. This area is enclosed by the ramps of the adjacent regional road and the state railroad. The building dealt with is located about $25 \mathrm{~m}$ from the regional road centerline.

\subsection{Hydrogeology}

The regional aquifer is the phreatic Plio-plistocene sandy aquifer. The chief components of the aquifer are relatively thick series of calcareous marine sandstone, calcareous continental sandstone and unconsolidated sands in alteration. The aquifer is underlined at approx. $150 \mathrm{~m}$ depth by the impermeable Saqiya bed which composed of marls, silty shales and clays. The aquifer is overlain by recent sediments deposited by the Ayalon stream. The main characteristic of the aquifer is the existence of local confining layers which may serve as seasonal perched interaquifers. According to the Yearly published by the Israeli Hydrological Service of Israel [1] the regional water table is located 15$20 \mathrm{~m}$ below surface. 


\subsubsection{Soil water analysis}

Soil cores were taken at the end of the winter (April) to a depth of $3.6 \mathrm{~m}$ in the vicinity of the building. Values of gravimetric water content were 0.28 to 0.38 . As mentioned before, summer measurement (July) revealed low water content values.

\section{Failure of the building}

\subsection{The reduction of soil capacity}

Probable causes to soil deterioration are changes in topography and land use at the vicinity of the structure together with the natural hydrological condition of the area. Due to bad drainage conditions surface water tend to concentrate in the closed area east to the residential area and forced to infiltrate into the ground.

Water status in the soil profile is varied according to the season. During the winter water is accumulated above the local clayey lens, increasing water content to a high saturation degree. The spatially intermittent characters of clay lens enable deep drainage through the surrounded permeable sand during the summer. Comparing 1936 map (fig. 3a) with the recent situation (fig. 3b) show that a substantial change was done in the area surrounding the building The adjacent road which was renewed six years ago and its acoustic wall inhibits drainage of surface runoff from the west side of the residential area toward its natural drainage base in the east. Moreover, construction activities themselves changed soil consolidation and soil density while creating residual deformability. Soil shearing strength has been decreased later by the vibrations of the heavy traffic ( $\sim 0.5$ million vehicles per day) passed in the road and highway. Activities in the close vicinity of the building like conveying the local runoff water directly to the building and intense excavations (gas reservoir) near the building could also increase soil water content, raised soil deformability, reduced the friction resistance of the soil bringing to law bearing capacity of the piles.

\subsection{Failure details}

Statically analysis of the foundation, based on the soil tests, the measurements of the dimensions of the building, was carried out, in order to evaluate the safety factor of it. The actual loads on the piles were calculated and the bearing capacity of the piles was established based on friction stress based on the water content of the soil (fig. 6). In the diagrams one can see the dependency of the bearing capacity of the piles on the Index of Consistency $\left(\mathrm{I}_{\mathrm{L}}\right)$. The values of the soil friction for different values of $\mathrm{I}_{\mathrm{L}}$ were taken from [2]. The respective water content is also shown in the diagrams. It was found that at water content $\mathrm{W}=0.3$ the capacity of the piles is sufficient to carry the actual loads (safety factor $\mathrm{SF}=1$ ) but for $\mathrm{W}=0.33$ it drops to $80 \%$ and for $\mathrm{W}=0.38$ it is only about $60 \%$ of the actual load. Actual measurements and geometrical calculations show that the maximal vertical settlement was $\sim 35 \mathrm{~cm}$, five times the permissible settlement for 
reinforced concrete structure which is $\mathrm{S}_{\mathrm{U}}=8 \mathrm{~cm}$. The permissible relative difference in limited settlement $(\Delta \mathrm{S} / \mathrm{L})_{\mathrm{U}}$ is 0.002 . In our case this value was between 0.03 to 0.04 [3].

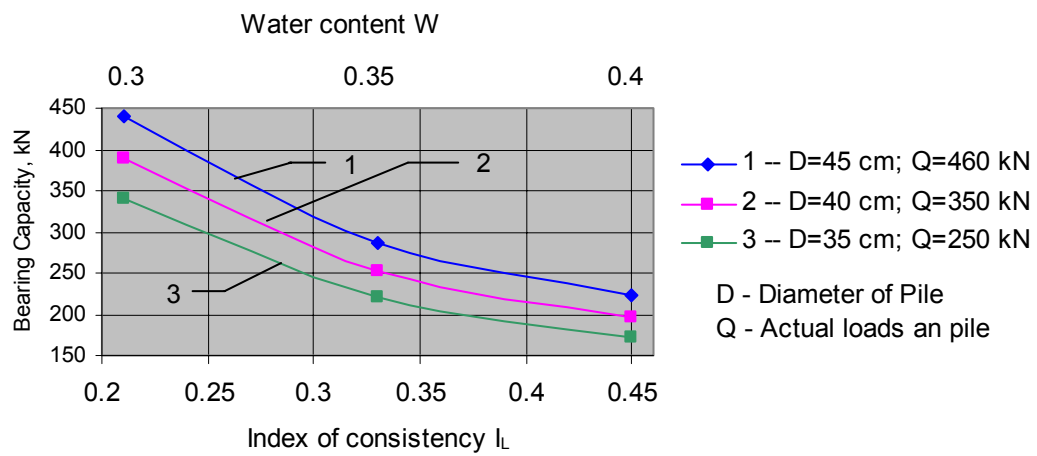

Figure 6: Functional dependence of Bearing capacity of the piles and Index of consistency.

As the piles were already under designed, the reduction of capacity due to increase of the water content disturbed their delicate state of balance. At the same time, the residual deformations due to vibrations caused by the heavy traffic on the adjacent regional road contributed, also, to the large settlements of the building.

\section{Conclusions}

On January 2006 a residential building in the southern part of Tel Aviv failed due to large settlements of its foundations. The largest settlement of $35 \mathrm{~cm}$ occurred at the south-east corner. As a result one of 5 sections of the building has to be demolished. The direct reason of the event was a combination of inadequate design of the foundations and the reduction of the soil capacity due to change if the water drainage regime. The foundations, although without sufficient safety factor, were in a fragile balance throughout 4 decades. But as the water content of the soil changed to the worse that fragile balance was disturbed, the deformability of the subsoil increased and its bearing capacity decreased, thus the foundation no longer could carry the building.

\section{Acknowledgements}

The authors are grateful to Dr. Y. Eshel from the Samaria and Jordan Rift R\&D Center for his assistance and to Engineer D. Rabinovicth, of the Municipality of Tel Aviv, for his support. The authors consulted the soil and foundations 
Engineers, D. David, Z. Diamandy, A. Blank, and D. Blechman of the Israeli Institute of standards, soils laboratory, who conducted the soil test, and to Eng. A. Gimburg from the Samaria and Jordan Rift R\&D Center for his drawings.

\section{References}

[1] Israeli Hydrological Yearly for 2003/04, Jerusalem, 2006

[2] Dolmatoff B. Soil mechanics and foundation, Stroizdat, Moscow, 1982

[3] Gersevanoff Researches Institute of foundations and underground structures, Hand book for the design of foundations for buildings and structures, Stroizdat, Moscow, 1986 